\title{
Editorial Announcement
}

\author{
Ravi P Agarwal
}

Correspondence: agarwal@fit.edu Florida Institute of Technology, USA
I am excited to inform all previous and future contributors, as well as readers, that the journal Boundary Value Problems has been transferred to the international publisher Springer, Science + Business Media, to continue publication as part of the new SpringerOpen range of fully open access journals.

I am honored to continue to act as Editor-in-Chief, serving alongside editorial board members from various well-renowned institutions. In joining SpringerOpen, we are confident that the journal will have a much stronger impact in the near future. Based on the many high quality articles published since 2005, it is our belief that our impact factor will be further strengthened.

The journal Boundary Value Problems is a peer-reviewed journal. The aim of Boundary Value Problems is to provide a forum to promote, encourage, and bring together various disciplines which use the theory, methods, and applications of boundary value problems. Boundary Value Problems will publish very high quality research papers on boundary value problems for ordinary, functional, difference, elliptic, parabolic, and hyperbolic differential equations. Papers on singular, free, and illposed boundary value problems, and other areas of abstract and concrete analysis are welcome. In addition to regular research papers, Boundary Value Problems will publish review articles.

By continuing to publish as an open access journal, all articles published in the journal Boundary Value Problems will be freely available for anyone to view as before. The existing coverage in the indexing and abstracting services will also continue uninterrupted.

All manuscripts submitted to Boundary Value Problems will be subjected to a quick and impartial closed peer-review process. The Editor-in-Chief/Associate Editors will initially examine the manuscripts to check the suitability of papers. Based on reviews, and the recommendations from the assigned editors, the Editor-in-Chief will inform authors regarding acceptance of their manuscripts. Upon acceptance, the articles will appear online immediately.

I am delighted to be taking the journal Boundary Value Problems forward with SpringerOpen and look forward to disseminating high quality research developments to the academic community.

Ravi P Agarwal

(Editor-in-Chief) 